\title{
Uma tradição de papel: novas achegas para a história das bibliotecas eclesiásticas em Portugal
}

\author{
Luana Giurgevich \\ Doutora; CIUHCT, Faculdade de Ciências, Universidade de Lisboa, Lisboa, Portugal; \\ luana.giurgevich@gmail.com
}

\begin{abstract}
Resumo: Este trabalho visa discutir a definição de biblioteca eclesiástica no panorama bibliográfico português através do conceito/função de seleção. $O$ ponto de partida é um levantamento sistemático de catálogos, inventários e outras listas de livros de cerca de 400 bibliotecas de congregações religiosas portuguesas. A base de dados produzida conta com mais de 900 espécies bibliográficas. $\mathrm{O}$ artigo abre-se com uma breve revisão bibliográfica em torno das questões que envolveram a evolução da história das bibliotecas em Portugal. $\mathrm{Na}$ segunda parte, apresenta-se a rede de bibliotecas eclesiásticas no panorama de estudos sobre bibliotecas. A terceira parte mostra como a função de seleção afetou o funcionamento interno das bibliotecas eclesiásticas ao longo da sua existência secular. A quarta parte analisa o post-mortem institucional das bibliotecas eclesiásticas e a dispersão destas como resultado de processos seletivos externos (1759-1834). As conclusões sublinham a importância de um trabalho de reconstrução histórica de coleções dispersas e a vitalidade intrínseca da biblioteca eclesiástica.
\end{abstract}

Palavras-chave: Congregações religiosas. Catálogos, inventários e bibliografias. Coleções. Livro antigo. Secularização.

\begin{abstract}
"To the trained eye, each [list] contains a story: how the list maker imagines the place for which he has packed the items, his way of seeing the world that lies behind a particular kind of ordering, the secrets being hidden by omissions from the list."
\end{abstract}

(WILSON-LEE, 2019, p. 7)

\section{Introdução}

A angústia do homem em frente do caos da vida levou-o constantemente a descrever, inventariar e organizar o conhecido. A preocupação pelo caos foi aumentando ao longo dos séculos com a crescente produção de livros e de documentos do progresso intelectual e material da humanidade. A invenção da imprensa contribuiu assim para incrementar a necessidade de bibliografias e, hoje em dia, com o rápido desenvolvimento tecnológico e a evolução das 
ferramentas de acesso às bibliotecas, existem on-line milhares de bases de dados, catálogos e outros instrumentos bibliográficos.

Considerando a palavra "bibliografia" na sua aceção mais alargada, existiram várias expressões que, na época moderna, se usavam para indicar este específico género literário: biblioteca, catálogo, inventário, repertório, léxico, thesaurus, dicionário, índice, entre outras. A exatidão da descrição catalográfica dependia das finalidades das bibliografias: algumas eram mais focadas nos aspetos editoriais dos livros (número de volumes, formato, valor, etc.), outras no valor cultural e científico dos livros referenciados. Listas de livros recomendados, bibliografias temáticas ou linguísticas, índices de livros proibidos, catálogos de venda de livreiros e impressores, repertórios bibliográficos nacionais (as assim-chamadas bibliothecae) faziam todos parte de um género literário de fronteiras muito flexíveis, que hoje aparece quase completamente desvinculado de uma ideia de biblioteca física. Em realidade, todas estas bibliografias tiveram um impacto enorme na formação de bibliotecas antigas e, em contexto religioso, os próprios padres bibliotecários produziram regularmente bibliografias especializadas nas quais se apoiavam para a criação e atualização das suas bibliotecas. As bibliografias eram necessárias para oferecer uma organização coerente à coleção de livros e para respeitar os interesses maiores da congregação religiosa. Neste contexto, não são excluídos os livros potencialmente controversos e proibidos, cuja leitura era obrigatória nem que fosse para fazer uma seleção adequada. Por isso, se a bibliografia era um ato de seleção imprescindível, a biblioteca eclesiástica era o resultado ponderado de camadas de seleções e leituras. As escolhas do padre bibliotecário pressuponham o conhecimento da comunidade e o desenvolvimento de uma específica sensibilidade ligada aos usos práticos dos livros, que era transmitida aos sucessivos bibliotecários.

Este artigo desenvolve o conceito de seleção como uma das principais funções constitutivas da biblioteca eclesiástica em Portugal até ao século XIX e, outro tanto, considera a dispersão das bibliotecas das congregações religiosas portuguesas e a consequente constituição das bibliotecas liberais como resultado de outro complexo processo seletivo. Os instrumentos bibliográficos produzidos 
(catálogos, inventários e outras bibliografias) foram elementos essenciais para o cumprimento desta função.

$\mathrm{Na}$ base deste trabalho está um levantamento exaustivo de catálogos, inventários e outras fontes sobre bibliotecas eclesiásticas portuguesas, que abrange um universo constituído por cerca de 400 bibliotecas (GIURGEVICHLEITÃO, 2016). O levantamento abre o caminho para o estudo comparativo destas bibliotecas e para a reconstrução dos seus acervos, e, além disso, deixa entrever uma tipologia de biblioteca "ativa", "viva" e "seletiva". A definição de biblioteca eclesiástica não pode reduzir-se às paredes físicas da sua "casa de livraria", nem ao seu recheio material. Embora a biblioteca da comunidade tivesse um espaço próprio e bem definido, os próprios religiosos viam-na como um organismo ramificado e flexível, em constante diálogo com as novidades do mundo laico ${ }^{1}$.

\section{Premissa historiográfica: os estudos sobre bibliotecas em Portugal}

O estudo das bibliotecas antigas foi inserido só recentemente num quadro intelectual mais abrangente apto a contribuir à história das ideias e das mentalidades. Percorrendo a bibliografia especializada, durante grande parte do século XX, as bibliotecas eram apresentadas como achados isolados. O encontro fortuito de catálogos por parte de investigadores familiarizados com as fontes documentais e arquivistas em posições privilegiadas marcaram o panorama dos estudos.

No contexto europeu, as primeiras tentativas de recenseamento de bibliotecas desenvolveram-se, de facto, num âmbito bibliológico e biográfico (BAILLY, 1828; EDWARDS, 1869; FRANKLIN, 1867-1876). Em Portugal, os primeiros estudos sobre bibliotecas apareceram em trabalhos de carácter "arqueológico" oitocentista, onde se entrelaçavam estreitamente as relações entre documentação histórica, bibliografia e recuperação de antiguidades (VILHENA BARBOSA, 1874; AZEVEDO, 1902; VITERBO, 1902). Uma constante, nunca esquecida, foi a história das "bibliotecas patrimoniais" atuais. Conhecer melhor a história dos acervos, a criação dos fundos de livro antigo e as origens constitutivas destas bibliotecas foi uma prioridade para várias 
instituições. Desde muito cedo, as bibliotecas patrimoniais foram objeto de estudos exploratórios e subsídios. Entre 1892 e 1902, Teófilo Braga explorou a história da biblioteca da Universidade de Coimbra, contextualizando a sua evolução até ao século XVIII (BRAGA, 1892-1902). Em 1907, Sampaio Bruno descreveu a Real Biblioteca Pública do Porto (BRUNO, 1906-1907). Em 1917, Francisco Nogueira de Brito traçou a história da Biblioteca Nacional de Portugal através da consideração de "livrarias notáveis" de particulares (NOGUEIRA, 1917). A estes estudos pioneiros seguiram-se muitos outros, que criaram uma sólida tradição historiográfica (DOMINGOS, 1995; CABRAL, 2014).

A partir da segunda metade dos anos '50, o interesse pelas bibliotecas começou a ser cultivado de uma forma mais sistemática, e especialmente nos estudos medievais (MARTINS, 1955; MARTINS, 1956; PEIXOTO, 1957; PEREIRA, 1964-1966; PEREIRA, 1967-1969). Nesta fase, a história das bibliotecas apresentava-se como uma área interdisciplinar, fortemente marcada pelos trabalhos desenvolvidos noutros ramos da história (artística, científica, social, diplomática, religiosa e económica). A impressão geral que ressalta é que cada estudioso seguia autonomamente um percurso metodológico próprio.

Nos anos '60-70, o panorama continuou a diversificar, com pesquisas que utilizavam o método quantitativo inserindo-o numa história política e cultural e que começavam, em especial, a considerar as bibliotecas de particulares categorias de leitores e até de personagens desconhecidas e anónimas. Um exemplo é representado pelo trabalho de Maria Adelaide Salvador Marques sobre a fiscalização das bibliotecas operada pela Real Mesa Censória, que conjuga a análise descritiva com os novos instrumentos da análise quantitativa (MARQUES 1964).

Foi só a partir da década de Oitenta do século XX que os investigadores portugueses começaram a recorrer, com mais frequência, às bibliotecas como ferramentas de conhecimento histórico (ANDRADE, 1981-1984; CAEIRO, 1981; RAMOS, 1981; COSTA, 1983; COSTA, 1984; NASCIMENTO, 1985; BARBOSA, 1989). A grande proliferação de estudos sobre bibliotecas e sobre a circulação dos livros, e os avanços feitos (especialmente em termos de método), 
foram logo salientados nas bibliografias da área (LISBOA, 1997; 350 títulos, 1997).

Nesta fase de maior consciência da importância das bibliotecas como instrumentos de investigação, muito foi feito no conhecimento de alguns grandes bibliófilos e colecionadores compulsivos. Neste leque de personalidades privilegiadas encontram-se Fr. Manuel do Cenáculo (VAZ-CALIXTO, 2006; VAZ, 2009; VAZ, 2013; OLIVEIRA, 2014), o Cardeal Saraiva, o bispo Dom João de Magalhães e Avelar (DANTAS, 1925; OLIVEIRA, 2000), e mais recentemente Dom Teodósio I (NASCIMENTO, 1994; BUESCU, 2016). Também as bibliotecas régias (ALMEIDA, 1991; BUESCU, 2004; BUESCU, 2007; RAIMUNDO, 2008) e os hábitos de leitura das mulheres (CEPEDA, 1987; LOUREIRO, 1993; CARVALHO, 1997; LOUREIRO, 1998-1999; CASTRO, 2001; SANTOS, 2002) fazem parte de linhas de investigação sobretudo recentes.

De um ponto de vista bibliográfico, a investigação produziu um quadro parcial e fragmentário, mais vinculado à especificidade dos casos do que à individuação de orientações de grande alçada. As narrativas sobre as bibliotecas portuguesas privilegiaram algumas figuras de colecionadores e poucas instituições, relegando outros possuidores de livros a contribuições esparsas. Muitas vezes, as coleções de livros de algumas personalidades fundiam-se com a história institucional das bibliotecas patrimoniais portuguesas, tornando difícil uma discriminação definitiva e redutora.

\section{Um mundo subterrâneo: as bibliotecas eclesiásticas de Portugal}

Não surpreende também que a história das bibliotecas eclesiásticas tenha sido contada, até recentemente, em estudos e monografias de notável valor intelectual, contudo dedicados a realidades peculiares ou temporalmente delimitadas (MADAHIL, 1923-1924; MADAHIL, 1942; MAGALHÃES BASTO, 1940; LOPES, 1978; RAMOS, 1981; NASCIMENTO, 1991; NASCIMENTO, 1995; CARVALHO, 1995; CARVALHO, 1998; CAMPOS, 2015, entre outros). 
A primeira referência à categoria de "biblioteca $(s)$ eclesiástica $(s)$ ", no seu plural, apareceu já em 1923, no trabalho de António Anselmo, intitulado emblematicamente Bibliografia das bibliografias portuguesas ${ }^{2}$. A denominação de "bibliotecas eclesiásticas" foi geralmente utilizada para designar todas as diferentes tipologias de bibliotecas que pertenceram à Igreja Católica: as bibliotecas capitulares de catedrais/cabidos ou de colegiadas, as bibliotecas diocesanas e episcopais, as bibliotecas monásticas e conventuais, as bibliotecas de colégios religiosos e de outras instituições de ensino, as bibliotecas de irmandades, as bibliotecas de confrarias e misericórdias, e também as bibliotecas privadas de indivíduos vinculados à Igreja (ANSELMO, 1923; ANDRADE, 1981, v. 1, p. 331; NASCIMENTO, 1993, p. 273; GOMES, 2002, p. 269).

Dentro deste universo tão variegado, as bibliotecas das congregações religiosas sobressaem por várias razões. A principal é, sem dúvida, a organização de uma eficiente rede de bibliotecas (cerca de 400 até 1834), alimentada por um sistema estável de crescimento e tutela das coleções de livros. Se a cartografia geral desta rede foi exposta na publicação Clavis bibliothecarum (GIURGEVICH-LEITÃO, 2016), ainda falta uma visão de conjunto para as outras tipologias de bibliotecas organizadas pela Igreja.

A historiografia portuguesa estudou de forma mais sistemática por volta de 40 bibliotecas eclesiásticas, e só uma fração reduzida destas pode mostrar uma tradição de estudos conspícua. Entre esta "plêiade" de bibliotecas, são as grandes instituições religiosas a sobressair: o Mosteiro de São Martinho de Tibães, o Mosteiro de Alcobaça, o Mosteiro de Santa Cruz de Coimbra ou o Convento de Mafra, para citar alguns exemplos ${ }^{3}$. Se quantitativamente os estudos sobre as bibliotecas das congregações religiosas são reduzidos, o tema da biblioteca eclesiástica era um fio condutor que percorria "subterraneamente" as discussões relativas às outras bibliotecas existentes no país (régias, universitárias, privadas, etc.). As conexões com as bibliotecas das congregações são inúmeras: basta pensar na história da Universidade de Coimbra, que desde a sua fundação, ficou intimamente ligada às bibliotecas dos mosteiros e dos 
colégios das ordens religiosas, que podiam compensar eventuais faltas de livros (MADAHIL, 1932; GOMES, 1991; MUSSER, 2012).

Até 1834, o panorama cultural português foi fortemente afetado pelos interesses das congregações religiosas. O mercado português não só captava os seus gostos, mas alimentava-se dos livros que as congregações religiosas faziam chegar a Portugal e que revendiam no mercado nacional. Os livros entravam a fazer parte do circuito de venda laico por razões diversificadas (autorizadas pelas próprias congregações, mas também ilegalmente após roubos ou compras ilícitas). Verbas regulares para o crescimento das bibliotecas, quase ilimitadas e vitalícias, ajudaram a criar uma rede capilar de bibliotecas que chegava a cobrir todo o território nacional. Este facto resulta ainda mais evidente se pensarmos que pelo menos dez destas bibliotecas possuíam mais de 20.000 volumes e três dezenas mostraram números acima dos 5.000 volumes. Todos estes números não incluem as bibliotecas-satélites das bibliotecas institucionais das várias casas religiosas: em alguns casos, a posse individual de obras podia ser tão esmagadora que a biblioteca da comunidade parecesse até escassa: a Casa Professa de São Roque, em 1760, tinha 7.739 volumes na biblioteca institucional e outros 6.162 volumes nas bibliotecas privadas dos padres (GIURGEVICH-LEITÃO, 2016, p. XXI). Estes dados tornam o universo das congregações religiosas numa realidade única no seu género.

\section{A seleção dos livros (I): a vida interna das bibliotecas eclesiásticas}

A grande multiplicação dos espaços de conservação dos livros leva a uma imagem plurifacetada da biblioteca eclesiástica: embora ela tivesse tido um espaço de gestão centralizador, de facto, encontrava-se fortemente deslocada. Por esta razão, era uma necessidade das congregações desenvolver eficientes instrumentos bibliográficos que interligassem a biblioteca "comum" e as bibliotecas particulares/especializadas que a rodeavam.

Falar da biblioteca eclesiástica como o resultado de seculares camadas de seleções leva a dois importantes corolários: 1. o primeiro é que estas bibliotecas não eram simples armazéns de livros herdados pelas mais variadas vias (legados de benfeitores, doações, espólios de religiosos, etc.); 2. e o segundo é que estas 
coleções de livros não tinham como objetivo a perpetuação de cânones literários arcaicos, ao contrário, apostar na seleção significava precisamente atualizar as coleções.

A biblioteca eclesiástica era objeto de escolhas, propostas e debates acesos, que envolviam, em primeiro lugar o bibliotecário e os seus superiores, mas chegavam também aos outros membros da comunidade. A biblioteca institucional de uma casa religiosa unia os interesses de um target de leitores bem definido e ativo na sua constituição. Este processo de seleção não afetava em si somente as bibliotecas das comunidades religiosas: tinha um impacto maior, que se enraizava no tecido cultural do país, através do mercado do livro nacional onde os livros que as congregações descartavam eram revendidos. A redação de bibliografias era uma prática consolidada no quotidiano dos religiosos. Eram várias as formas das bibliografias: inventários patrimoniais; catálogos de bibliotecas (incluindo catálogos topográficos, bio-bibliográficos e linguísticos); índices de livros proibidos; catálogos de venda de impressores; e, até, sumários de publicações recentes. A grande presença de obras miscelâneas, de índices e de trabalhos com referências cruzadas nas bibliotecas eclesiásticas é mais um elemento que denota a existência de um processo seletivo praticado com regularidade, minuciosamente, inspirado pela crescente experiência de especialistas bibliotecários. Não é por acaso que as primeiras obras de biobibliografia fossem redigidas no âmbito de uma tradição eclesiástica ${ }^{4}$, nem que os religiosos bibliotecários fossem procurados como bons entendedores de livros e hábeis conselheiros de compras (GIURGEVICH, 2017).

A redação de bibliografias e o conhecimento delas fazia parte das tarefas básicas do bibliotecário. O melhoramento e a atualização dos instrumentos de descrição era uma das atividades principais deste cargo. Por um lado, as bibliografias permitiam controlar o acesso aos livros; do outro, permitiam a criação arquivos de títulos de desiderata. O bibliotecário era obrigado a examinar os catálogos de venda dos livreiros portugueses e internacionais na busca de novidades literárias. O bibliotecário tinha, ainda, a obrigação de orientar as seleções para que pudessem preencher as futuras faltas da biblioteca. 
É por esta razão que extravios, descaminhos e perdas de livros era frequentemente assinalados nos catálogos e nos inventários ${ }^{5}$.

As escolhas do bibliotecário eram avaliadas pelos superiores e sujeitas a aprovação, facto que refinava ainda mais o processo de seleção das obras. As escolhas do bibliotecário podiam até basear-se em sugestões e pedidos provenientes de outros religiosos (como os mestres), alargando o processo seletivo a outros agentes.

As maiores bibliotecas podiam ser consultadas através diferentes tipologias de catálogo, para satisfazer as necessidades do leitor mais exigente. Os catálogos podiam ser ordenados alfabeticamente pelos autores ou títulos, ou em ordem sistemática de temáticas e também cronologicamente ou topograficamente. Alguns bibliotecários optavam até por acompanhar estas listas com notas críticas ou explicativas sobre os autores das obras possuídas. Alguns catálogos apresentavam sistemas de índices de nomes e temas detalhados. Havia também uma grande preocupação em listar folhetos soltos ou "volantes", organizando complexos aparatos de referências cruzadas e relações entre os itens listados ${ }^{6}$. Dois exemplos, entre outros, mostram claramente esta grande diversidade de instrumentos de consulta: 1. a biblioteca do mosteiro beneditino de Tibães ${ }^{7} ; 2$. e a biblioteca oratoriana da Casa de Nossa Senhora das Necessidades em Lisboa $^{8}$. Este tipo de catalogações implicava que o bibliotecário fosse leitor insaciável, de grande cultura e erudição. O bibliotecário oratoriano da Casa das Necessidades, o Padre Domingos Pereira (séc. XVIII), redigiu catálogos alfabéticos, temáticos, mas também bibliografias mais específicas agrupadas por produção nacional. Todos estes instrumentos eram essenciais na programação de novas aquisições e na busca de livros raros (CRISTINO, 1988).

A utilidade de uma obra era condição essencial para que o livro fosse comprado, usado e conservado. A prática regulamentada de organizar leilões de livros (internos a uma instituição ou promovidos entre casas de diferentes ordens religiosas), era outra faceta dos processos seletivos que envolviam as bibliotecas eclesiásticas. Livros desatualizados, inúteis ou simplesmente em excesso, voltavam a ser postos em circulação e eram redistribuídos entre os religiosos da 
comunidade, mas também podiam atingir outras ordens religiosas e até um público mais alargado de laicos. Estes mecanismos de funcionamento/seleção da biblioteca facilitavam uma circulação de livros para fora das instituições eclesiásticas, amplificando o seu alcance. Cada biblioteca eclesiástica era, portanto, uma história de acumulação, mas ainda mais de seleção.

\section{A seleção dos livros (II): a época das inventariações estatais (1759-1834)}

O caos, afinal, chegou abruptamente com os sequestros e as arrecadações dos bens dos colégios jesuítas em 1759. A inventariação das bibliotecas eclesiásticas coincidia com a apropriação de uma inteira cultura, e que até lá estava nas mãos de um específico grupo de colecionadores. Esta consciência insinuou-se lentamente nas altas esferas do governo português.

Foi entre 1759 (data da expulsão dos jesuítas) e 1834 (data de extinção de todas as ordens religiosas masculinas) que a vida interna das bibliotecas eclesiásticas foi afetada por imposições externas ao seu normal decurso. O crescente interesse político pelas bibliotecas das congregações religiosas levou sucessivos governos a produzir um grande número de inventários, que dessem conta do universo de livros existente nas instituições eclesiásticas do país. Este fenómeno de inventariações mostra uma estreita ligação entre a bibliografia e a estrutura política, económica e espiritual de Portugal nesta determinada época.

Os critérios de seleção desenvolvidos nesta altura determinaram o futuro de muitas coleções de livros. Foram produzidas específicas legislações para uniformizar o processo de inventariação das bibliotecas eclesiásticas: a intervenção estatal tinha, claro, diretrizes próprias alheias aos ditames das constituições das ordens religiosas que por séculos tinham direcionado e regulamentado o crescimento destas bibliotecas. Para satisfazer às exigências do governo, os inventários tinham que fornecer precisas notícias descritivas sobre a natureza e as caraterísticas das coleções de livros. A grande variedade cultural dos recursos humanos envolvidos nas inventariações influenciou a qualidade destas bibliografias: $\mathrm{o}$ ato de registrar ficou fortemente ligado a uma coordenação racional e a uma imprescindível componente seletiva pessoal. $\mathrm{O}$ fator humano foi determinante na preservação/destruição de determinados livros 
e, também, na delineação geral da cultura portuguesa atual. Por um lado, o desmembramento das bibliotecas eclesiásticas levou a uma perca da memória coletiva (séculos de aquisições e compras de livros), do outro, estas bibliotecas foram utilizadas para a construção de uma memória ex-novo, ligada ao mito das descobertas e, sobretudo, laica.

\subsection{A administração pombalina e o "espanto" das bibliotecas eclesiásticas}

A administração pombalina encontrou o seu alimento nesta laicização. As bibliotecas dos jesuítas e de outras congregações religiosas como os regrantes de Santo Agostinho, ricas e bem apetrechadas, tornaram-se num dos principais objetivos das reformas do Marquês de Pombal. Foi no âmbito da expulsão da Companhia de Jesus (1759) que o governo tomou consciência da grandeza das bibliotecas jesuítas, até daquelas presentes em colégios menores. Os livros, espalhados por todas as dependências colegiais, mostravam quanto o livro fazia parte da vida quotidiana dos religiosos. Cada instituição era um mundo de bibliotecas ${ }^{9}$. Dado que as bibliotecas não eram o objeto principal das primeiras inventariações do património jesuítico, as relações de livros apresentavam-se como relatórios apressados e sintéticos, mas o olhar agudo das comissões incumbidas pelas inventariações fez com que a catalogação das bibliotecas maiores ficasse logo executada. O carácter incompleto dos primeiros autos de inventário era evidente: a descrição de duas grandes bibliotecas como a da Casa Professa de São Roque e a do Colégio de Santo Antão precisavam de peculiares cuidados. Rapidamente, foram contratados especialistas em livros para proceder à produção dos catálogos destas bibliotecas ${ }^{10}$. Os especialistas escolhidos faziam parte da corporação dos mercadores de livros e dos professores. É de destacar um alto grau de profissionalismo no processo de catalogação das bibliotecas eclesiásticas, que se tornou progressivamente mais preciso. Aos olhos do Marquês de Pombal revelava-se crucial a afirmação do papel de referência que estas bibliotecas desempenharam no país e, especialmente, no âmbito do ensino nacional. A reforma do sistema de ensino tinha que partir de aí. Neste contexto, o recém-fundado Colégio dos Nobres iria ser o depositário dos livros de algumas importantes instituições da Companhia. O Marquês tinha mandado 
proceder a uma ação de recolha dos melhores livros da tradição portuguesa conservados "em quaisquer Bibliothecas Publicas ou Particulares, destes Reinos, e seus Dominios", com o objetivo de serem reimpressos na imprensa do Colégio dos Nobres ${ }^{11}$. Nesta busca de exemplares pode-se entrever, embora num estado ainda embrionário, a fiscalização das bibliotecas operada pela Real Mesa Censória. O interesse suscitado pelas bibliotecas jesuítas retomou força entre 1765-1766, anos em que circularam cópias dos primeiros inventários de sequestro e novos inventários de bibliotecas que estavam ainda à espera de ser inventariadas.

O Marquês de Pombal estava elaborando um programa cultural, cujas principais linhas de orientação, se resumiam num crescente controlo das bibliotecas existentes no país e da circulação dos livros. Tornou-se por isso fundamental que, a nível nacional, se definisse uma instituição que gerisse a fiscalização de todas as bibliotecas do reino. Subjacente a este programa estava a criação da Real Mesa Censória, que se tornou realidade em 1769. A sua ação foi crucial: definiu ponto por ponto um modelo nacional a ser implementado na inventariação de bibliotecas ${ }^{12}$. A aplicação do modelo não era tarefa fácil, sobretudo pelas diferenças existentes entre as coleções de livros, mas também pela variedade cultural dos inventariantes envolvidos. O respeito do modelo foi deixado ao arbítrio dos possuidores, não sendo, desta vez, executado por agentes estatais e profissionais. No caso específico das bibliotecas eclesiásticas, o inventariante era quase sempre o religioso bibliotecário e, em sua ausência, a tarefa era destinada ao reitor ou vigário da instituição.

É neste contexto histórico que se insere a inventariação de outro conjunto de bibliotecas: tratava-se de algumas das bibliotecas dos Cónegos Regrantes de Santo Agostinho, instituições extintas pela bula do Papa Clemente XIV em 1770. A gestão do património era dirigida pelo Cardeal da Cunha, Arcebispo de Évora, Inquisidor Geral e fiel seguidor do Marquês. A inventariação das bibliotecas extintas e a transferência dos livros contou, neste último caso, com inventariantes qualificados (mercadores e livreiros). Os livros das bibliotecas agostinhas foram recolhidos numa única biblioteca: a do 
Convento de Mafra, onde os Cónegos Regrantes se tinham instalado por vontade régia.

\subsection{A ação da Junta do Exame do Estado Atual e Melhoramento Temporal das Ordens Religiosas e as novas regras de catalogação das bibliotecas eclesiásticas.}

Em 1789, foi criado um novo organismo estatal encarregado de exercer a reforma das ordens religiosas. A Junta do Exame do Estado Atual e Melhoramento Temporal das Ordens Religiosas impulsionou uma nova fase de inventariações com o objetivo de verificar o estado das bibliotecas religiosas. Se numa primeira fase as inventariações eram deixadas ao arbítrio dos religiosos bibliotecários, numa segunda fase, assinalada pelo decreto de José da Silva Carvalho, datado de 1823 , foi redigido um novo modelo de inventariação ${ }^{13}$. Os informadores principais dos funcionários estatais continuavam a ser os próprios religiosos, mas estes eram interrogados e questionados segundo um modelo estandardizado. O modelo insistia no tamanho das bibliotecas (em número de volumes), no estado de conservação/deterioramento dos livros, na manutenção das bibliotecas, e na integridade das coleções (referendo alterações, roubos, extravios, calamidades várias; temática sensível numa altura em que eram frequentes os saques operados pelas tropas francesas). Este tipo de monitorização das bibliotecas eclesiásticas não previa a redação de novos inventários, enquanto era mais oportuno incorporar diretamente os catálogos de biblioteca encontrados em loco. Desta forma, muitos catálogos de livraria ficaram nas mãos do pessoal do Estado ${ }^{14}$. A ação da Junta voltou em auge com o objetivo concreto de proceder à supressão, arrecadação e incorporação dos bens das ordens religiosas masculinas na Fazenda Nacional a 5 de Agosto de 1833. Foi um processo complexo, moroso e, sobretudo, destrutivo.

Se, até agora, as intervenções do estado visavam principalmente a obter informações concretas sobre as bibliotecas, concebidas como um todo (um conjunto de existências), com a extinção de 1834, o fator seletivo foi decisivo em termos de preservação/destruição dos livros. As escolhas feitas pelas comissões encarregadas nas inventariações não só condicionaram a feitura dos 
inventários, mas foram determinantes no desaparecimento de inteiras coleções de livros julgados de pouco valor ("velhos", "antigos", "usados", "insignificantes", "truncos", "inúteis") ${ }^{15}$. Na grande maioria dos casos, as equipas de avaliadores das bibliotecas não eram constituídas por peritos em matéria de livros. Esta situação mudou só a partir de 1836, com a crescente atividade do Depósito das Livrarias dos Extintos Conventos (BARATA, 2003), a qual propulsionou catalogações mais aperfeiçoadas e a contratação de recursos humanos mais qualificados, mas não impediu que tivessem sido perpetrados danos irreparáveis a valiosas coleções.

O sequestro dos bens eclesiásticos, a progressiva ingerência do Estado nas bibliotecas da Igreja e a secularização do ensino levaram, por um lado, ao desaparecimento de uma rede capilar de bibliotecas; por outro lado, levaram paradoxalmente à produção de um número relevante de catálogos/inventários, que são hoje, para muitas bibliotecas eclesiásticas desmembradas e dispersas, os únicos testemunhos da sua existência. Concluindo, a função seletiva marcou profundamente as primeiras fases de inventariação das bibliotecas eclesiásticas, no século XIX, mas também a formação de novas bibliotecas especializadas, que privilegiavam escolhas temáticas bem precisas (BARATA, 2003).

\section{Considerações finais}

Este artigo passou por três momentos cruciais da história das bibliotecas eclesiásticas de Portugal: a construção/vida interna das bibliotecas (Cap. 3), a destruição/dispersão das coleções ao longo dos séculos XVIII e XIX (Cap. 4) e o processo de reconstrução histórica (Caps. 1-2). As novas abordagens metodológicas, lançadas em Portugal, sobretudo a partir dos anos '90 do século $\mathrm{XX}$, aprofundam de forma mais sistemática o conhecimento dos acervos de livro antigo das bibliotecas patrimoniais portuguesas, tentando traçar o perfil das coleções e dos antigos possuidores. As bibliotecas antigas escondem-se por detrás de várias camadas de escolhas organizativas, obrigações financeiras e trabalhos de catalogação e seleção. Durante grande parte do século $\mathrm{XX}$, a atenção dos investigadores fixou-se no estudo de poucas bibliotecas, devido à localização afortunada de novos catálogos e inventários. O rápido excursus 
bibliográfico mostra como as bibliotecas das congregações religiosas faziam parte desta prática geral e fossem objeto de estudos soltos, que aumentavam o risco de perder de vista a complexidade da tradição bibliográfica eclesiástica. Durante muito tempo passou despercebida a existência de uma eficaz rede de bibliotecas, que era constituída por mais de 400 instituições eclesiásticas. A realidade de bibliotecas a investigar - literalmente - decuplicou. A pouca atenção que as bibliotecas eclesiásticas mereceram deve-se também a uma ideia de estagnação cultural de origem anticlerical fortemente enraizada no imaginário coletivo, a qual obscurecia a real vitalidade desta tipologia de bibliotecas. Embora a cartografia desta rede tinha sido recentemente clarificada, a maioria destas bibliotecas continua a estar inexplorada.

O leit-motiv do artigo é o conceito de seleção e a sua importância no binômio de construção e destruição das bibliotecas eclesiásticas.

Construção. A tradição das congregações religiosas tinha uma necessidade contínua de regulamentar, através de legislação própria, a constituição das suas bibliotecas. A promoção das bibliotecas se fazia acompanhar de uma intensa produção de diferentes bibliografias. Uma seleção cultural precisa e, provavelmente, nem sempre, neutral estava à base do desenvolvimento das bibliotecas. Por esta razão, estudar as bibliotecas eclesiásticas hoje significa também individuar os critérios e os métodos de seleção que foram praticados pelas congregações religiosas. A biblioteca eclesiástica resultou de seleções bem ponderadas: todos os livros que a formaram eram objeto de seleção ativa e atualização contínua (seja que entrassem por doação, seja que resultassem da natural redistribuição dos espólios dos religiosos).

Destruição. Uma análise do processo de desamortização dos bens religiosos e de sequestro das bibliotecas eclesiásticas mostra outra faceta do processo seletivo. Desta vez, trata-se de um processo seletivo externo, mais vasto, gerido pelo Estado, e de difícil controlo. Diferentes dinâmicas conduziram à dispersão das bibliotecas, mas o destino dos livros dependeu muito das avaliações feitas pelas comissões supressoras. As equipas estatais 
jogaram um papel crucial, sobretudo, numa primeira fase de seleção dos livros das congregações religiosas.

Reconstrução. Nem sempre através da inventariação/catalogação se conseguem ver os livros proibidos ocultados, os livros de escasso valor que foram ignorados, ou ainda outras lacunas mais ou menos intencionais. Este facto impulsiona o investigador a utilizar outras tipologias de fontes e de documentação. A reconstrução das colecções de livros das congregações religiosas é tarefa complexa, mas fazer a radiografia dos grandes colecionadores de livros e traçar a história da difusão dos livros nas bibliotecas são dois elementos essenciais para compreender um contexto social mais amplo e, no fundo, delinear a fisionomia de uma inteira cultura.

\section{Financiamento}

$\mathrm{O}$ projeto de pesquisa no qual se insere este estudo contou com o apoio da Fundação para a Ciência e a Tecnologia. Financiado por FCT, I.P. através do Projeto: UID/HIS/00286/2019.

\section{Agradecimentos}

O presente artigo é a elaboração da conferência de encerramento proferida no âmbito do V Seminário Internacional "A Arte da Bibliografia: A Bibliografia entre o local e global: perspectivas históricas e aplicadas" (UFPE, Recife, 6 e 7 de Dezembro de 2018), organizado pelo Programa de Pós-Graduação em Ciência da Informação da Universidade Federal de Pernambuco (PPGCI UFPE) e, por isso, quero agradecer uma vez mais a toda a comissão organizadora pela honra do convite e pela possibilidade de partilhar os resultados da minha pesquisa no Brasil. Este estudo é também fruto de um trabalho de investigação desenvolvido no CIUHCT ao longo de vários anos com o Prof. Henrique Leitão, que agradeço especialmente pelo apoio e incentivo constantes.

\section{Referências}

ALMEIDA, Luís Ferrand de. D. João V e a Biblioteca Real. Revista da Universidade de Coimbra, Coimbra, v. 36, p. 413-438, 1991. 
ANDRADE, António Alberto Banha de. A reforma pombalina dos estudos secundários (1759-1771). Contribuição para a história da pedagogia em Portugal. Coimbra: Universidade de Coimbra, 1981-1984. 2 vols.

ANSELMO, António Joaquim. Bibliografia das bibliografias portuguesas. Lisboa: Oficinas Gráficas da Biblioteca Nacional, 1923.

ANSELMO, Artur. História da edição em Portugal. I. Das origens até 1563. Porto: Lello \& Irmão 1991.

AZEVEDO, Pedro A. de. Um inventário do século XIV. O Archeologo Portugues, Lisboa, v. 7, n. 8/12, p. 223-234, 259-265, 305-308, 1902. Lisboa: Imprensa Nacional 1903.

BAILLY, Jean. Notices historiques sur les bibliothèques anciennes et modernes. Paris: 1828.

BARATA, Paulo. Os livros e o Liberalismo: da livraria conventual à biblioteca pública: uma alteração de Paradigma. Lisboa: Biblioteca Nacional, 2003.

BARBOSA, José de Abreu. A Biblioteca Geral da Universidade de Coimbra. ICALP. Revista do Instituto de Cultura e Língua Portuguesa, Lisboa, v. 1617, p. 161-169, jun./set. 1989.

BRAGA, Teófilo, Historia da Universidade de Coimbra nas suas relações com a Instrução Publica Portugueza. Lisboa: Typographia da Academia Real das Sciencias, 1892-1902. 4 vols.

BRITO, Francisco Nogueira de. Livrarias notáveis pertencentes a particulares: subsídios para a história da Biblioteca Nacional de Lisboa. Anais das Bibliotecas e Arquivos de Portugal, Lisboa, v. 3, n. 10-11, p. 45-63, 1917.

BRUNO, Sampaio. A Real Bibliotheca Publica do Porto. Serões, Lisboa, s. 2, v. 3, n. 16, Outubro 1906 e v. 4, n. 20, Fevereiro 1907.

BUESCU, Ana Isabel. A livraria renascentista de D. Teodósio I, duque de Bragança. Lisboa: Biblioteca Nacional de Portugal, 2016.

BUESCU, Ana Isabel. A Livraria Régia no tempo de D. Manuel. Alguns aspectos. In: CONGRESSO HISTÓRICO DE GUIMARÃES. D. MANUEL E A SUA ÉPOCA, 3., 2001, Actas [...]. Guimarães: Câmara Municipal de Guimarães, 2004. v. 4, p. 263-279.

BUESCU, Ana Isabel. Livros e livrarias de reis e de príncipes entre os séculos XV e XVI. Algumas notas. eHumanista: Journal of Iberian Studies, Santa Barbara, California, v. 8, p. 143-170, 2007. 
CABRAL, Maria Luísa. A Real Biblioteca e os seus criadores em Lisboa, 1755-1803. Lisboa: Biblioteca Nacional de Portugal, 2014.

CAEIRO, Francisco da Gama. Fontes portuguesas de formação cultural do Santo. Itinerarium. Revista Quadrimestral de Cultura, Lisboa, v. 27, n. 110111, p. 136-164, 1981.

CAMPOS, Fernanda Maria Guedes dos. Para se achar facilmente o que se busca. Bibliotecas, catálogos e leitores no ambiente religioso (séc. XVIII). Casal de Cambra: Caleidoscópio, 2015.

CARVALHO, José Adriano Moreira de Freitas. "Nobres leteras... fermosos volumes". Inventários de bibliotecas dos franciscanos observantes em Portugal no séc. XV: os traços de união das reformas peninsulares. Porto: Edição do Centro Inter-Universitário de História da Espiritualidade e do Instituto de Cultura Portuguesa-Faculdade de Letras da U.P., 1995.

CARVALHO, José Adriano Moreira de Freitas. Do recomendado ao lido: direcção espiritual e prática de leitura entre franciscanas e clarissas em Portugal no séc. XVII. Via Spiritus, Porto, Centro Interuniversitário de História da Espiritualidade-Instituto de Cultura Portuguesa da Faculdade de Letras da Universidade do Porto, v. 4, p. 7-56, 1997.

CARVALHO, José Adriano Moreira de Freitas. Da memória dos livros às bibliotecas da memória. I. Inventário da livraria de Santo António de Caminha. Porto: Faculdade de Letras-Centro Inter-Universitário de História da Espiritualidade, 1998.

CASTRO, Zília Osório de. Bibliotecas femininas. In: Congresso O Marques de Pombal e a sua epoca. Actas. Oeiras-Pombal: Camara Municipal, 2001. p. 447484.

CEPEDA, Maria Isabel Vilares. Os Livros da Rainha D. Leonor segundo o Códice 11.352 da Biblioteca Nacional. Revista da Biblioteca Nacional, Lisboa, s. 2 , v. 2, n. 2, p. 51-81, 1987.

COSTA, Avelino de Jesus da. A Biblioteca e o Tesouro da Sé de Coimbra nos séculos XI a XVI. Boletim da Biblioteca da Universidade de Coimbra, Coimbra, v. 38, p. 1-220, 1983.

COSTA, Avelino de Jesus da. A biblioteca do cabido da Sé de Braga, nos fins do século XV, e o seu tesouro em 1589. Anais da Academia Portuguesa da História, Lisboa, s. 2, v. 29, p. 627-660, 1984.

CRISTINO, Luciano Coelho. A Biblioteca Mariana dos Oratorianos de Lisboa (séc. XVIII). In: De cultu mariano saeculis XVII-XVIII: acta congressos mariologici-mariani internationalis in republica melitensi anno 1983 celebrati. Romae: Pontificia Academia Mariana Internationalis, 1988. v. VII, p. 111-128. 
CURTO, Diogo Ramada. As gentes do livro - Lisboa, século XVIII. Lisboa: Biblioteca Nacional, 2007.

DANTAS, Júlio. A livraria do bispo Avelar. Anais das Bibliotecas e Arquivos, s. 2, v. 6, n. 24, p. 206-207, 1925.

DOMINGOS, Manuela. Subsídios para a História da Biblioteca Nacional. Lisboa: Instituto da Biblioteca Nacional e do Livro, 1995.

DOMINGOS, Manuela. Livreiros de setecentos. Lisboa: Biblioteca Nacional, 2000.

EDWARDS, Edward. Free town libraries, their formation, management and history in Britain, France, Germany and America: together with brief notices of book-collectors, and of the respective places of deposit of their surviving collections. London: Trübner \& co, 1869.

FRANKLIN, Alfred. Les Anciennes Bibliothèques de Paris. Paris: Imprimerie Impériale, 1867-1876. 3 vols.

GIURGEVICH, Luana. Dos Alpes ao Atlântico. As ordens religiosas e seus intermediários na compra de livros. In: ALESSANDRINI, Nunziatella; RUSSO, Mariagrazia; SABATINI, Gaetano (org.). Homo est minor mundus. Construção de saberes e relações diplomáticas luso-italianas (sécs. XVXVIII). Lisboa: Fábrica da Igreja de Nossa Senhora do Loreto, 2017. p. 65-81.

GIURGEVICH, Luana; LEITÃO, Henrique. Clavis bibliothecarum. Catálogos e inventários de livrarias de instituições religiosas em Portugal até 1834. Lisboa: Secretariado Nacional para os Bens Culturais da Igreja, 2016.

GOMES, Saul. A solidariedade eclesial na promoção de escolares pobres a estudos universitários. O exemplo coimbrão nos séculos XIV e XV. In: Universidade(s). História, memórias, perspectivas. Actas do Congresso “História da Universidade de Coimbra". Coimbra: 1991. vol. 4. p. 195-234.

GOMES, Saul. Livros e alfaias litúrgicos do Tesouro da Sé de Viseu em 1188. Humanitas, Coimbra, v. LIV, p. 269-281, 2002.

LISBOA, João Luís. Sobre a investigação actual em história do livro e da leitura. Leituras. Revista da Biblioteca Nacional, Lisboa, s. 3, v. 1, p. $107-$ 108, abr./out. 1997.

LOPES, Fernando Félix. Lembranças avulsas da Livraria do Convento de S. Francisco de Xabregas. Itinerarium, Lisboa, v. 24, n. 100, p. 30-54, 142-170 (1978). 
LOUREIRO, Olímpia Maria da Cunha Loureiro. Os livros das monjas do Convento de S. Bento da Ave-Maria do Porto (finais do século XVIII). In: I Congreso Internacional del monacato femenino en España, Portugal y America (1492-1992). Leon: Universidad de Leon, 1993. t. 2, p. 719-730.

LOUREIRO, Olímpia Maria da Cunha Loureiro. Ler no feminino: memórias. Poligrafia, v. 7-8, p. 87-92, 1998-1999.

MADAHIL, António Gomes da Rocha. D. Pedro da Encarnação e a Livraria de Santa Cruz de Coimbra. Arquivo Coimbrão, Coimbra, v. 1, p. 71-83, 19231924.

MADAHIL, António Gomes da Rocha. A Biblioteca da Universidade de Coimbra e as suas marcas bibliográficas. Boletim Bibliográfico da Biblioteca da Universidade de Coimbra, Coimbra, v. 10, p. 161-231, 1932.

MADAHIL, António Gomes da Rocha. Inventário do mosteiro de Santa Cruz de Coimbra à data da sua extinção em 1834. O Instituto, Coimbra, v. 101, p. 445573, 1942.

MAGALHÃES BASTO, Artur de. Memórias soltas e inventários do Oratório de S. Clemente das Penhas e do Mosteiro de N. S.a da Conceição de Matozinhos, dos séculos XIV e XV, por Fr. João da Póvoa e outros (Ms. quinhentista do Arquivo Distrital do Porto). Boletim cultural da Câmara Municipal do Pôrto, Porto, v. 3, n. 1, p. 5-87, Março 1940.

MARQUES, Maria Adelaide Salvador Marques. A Real Mesa Censória e a cultura nacional: aspectos da geografia cultural portuguesa no século XVIII. Boletim da Biblioteca da Universidade de Coimbra, Coimbra, v. 26, p. 1-207, 1964.

MARTINS, Mário. Santo Agostinho nas Bibliotecas Portuguesas da Idade Média. Revista Portuguesa da Filosofia, Braga, t. 11, v. 1, fasc. 2, p. 166-176, abr./jun. 1955.

MARTINS, Mário. A Biblioteca de Alcobaça e o seu fundo de livros espirituais. In: Estudos de literatura medieval. Braga: Livraria Cruz, 1956. p. 257-283.

MATTOSO, José. Leituras cistercienses do século XV. Do Tempo e da História, Lisboa, v. 5, p. 101-141, 1972.

MUSSER, Ricarda. Building up Networks of Knowledge: Printing and Collecting Books in the Age of Humanism in the University City of Coimbra. In: ENENKEL, Karl A. E. (org.). Intersections. Interdisciplinary Studies in Early Modern Culture (Portuguese Humanism and the Republic of Letters), Leiden-Boston, v. 21, p. 113-128, 2012. 
NASCIMENTO, Aires. Livros e claustro no séc. XIII em Portugal: o inventário da Livraria de S. Vicente de Fora, em Lisboa. Didaskalia, Lisboa, v. 15, n. 1, p. 229-241, 1985.

NASCIMENTO, Aires. Livros e leituras em ambiente alcobacense. In: IX Centenário do Nascimento de S. Bernardo. Encontros de Alcobaça e Simpósio de Lisboa, Actas. Braga: Universidade Católica Portuguesa e Câmara Municipal de Alcobaça, 1991. p. 147-165.

NASCIMENTO, Aires. As livrarias dos príncipes de Avis. Biblos, Coimbra, v. 69, p. 265-287, 1993.

NASCIMENTO, Aires. A livraria de D. Teodósio I, Duque de Bragança. In: Congresso de História no IV Centenário do Seminário de Évora. Actas. Évora: Instituto Superior de Teologia-Seminário Maior de Évora, 1994. vol. 1. p. 209-220.

NASCIMENTO 1995. Monges, livros e leituras: modos de espiritualidade e preservação de textos. In: Os Beneditinos na Europa, $\mathbf{1}^{\mathbf{C}}$ Congresso Internacional (23 a 26 de Novembro de 1995), Santo Tirso. Santo Tirso: Câmara Municipal de Santo Tirso, 1995. p. 203-219.

OLIVEIRA, José António Mendonça Pereira de. Itinerários de uma biblioteca privada portuguesa (séculos XVIII-XIX). Revista Portuguesa de História do Livro, Lisboa, v. 4, n. 7, p. 25-48, 2000.

OLIVEIRA, Márcia. A biblioteca e os livros na obra de D. Frei Manuel do Cenáculo: notas sobre um bibliófilo. In: As bibliotecas portuguesas na transição para a modernidade, 1800-1850. Os intérpretes e as suas coleções. Lisboa: BNP-CHC, 2014. p. 23-52.

PEIXOTO, Jorge. Considerações sobre livrarias medievais. Arquivo de Bibliografia Portuguesa, v. 3, n. 12, p. 227-237, 1957.

PEREIRA, Isaías da Rosa. Livros de Direito na Idade Média. Lusitania Sacra, Lisboa, v. 7, p. 7-60, 1964-1966; v. 8, p. 81-96, 1967-1969.

RAIMUNDO, Ricardo A. Varela. Leituras régias: A livraria de D. Pedro II (1648-1706). In: MARTÍNEZ MILLÁN, José; LOURENÇO, Maria Paula Marçal (Org.). Las Relaciones Discretas entre las Monarquías Hispana y Portuguesa: Las Casas de las Reinas (siglos XV-XIX). Madrid: Ediciones Polifemo, 2008. v. 3, p. 1937-1958.

RAMOS, Luís A. de Oliveira. Os monges e os livros no século XVIII: o exemplo da Biblioteca de Tibães. Bracara Augusta, Braga, v. 35, n. 79-80, p. 489-499, 1981. 
SANTOS, Zulmira C. Percursos e formas de leitura 'feminina' na segunda metade do século XVIII. Revista da Faculdade de Letras. Línguas e Literaturas, v. 19, p. 71-110, 2002.

VAZ, Francisco. Os livros e as bibliotecas no espólio de D. Frei Manuel do Cenáculo: repertório de correspondência, róis de livros e doações a bibliotecas. Lisboa: BNP, 2009.

VAZ, Francisco. A biblioteca do Convento de Jesus (1755-1834): a herança de D. Frei Manuel do Cenáculo. In: As bibliotecas e o livro em instituições eclesiais. Actas do II e III Encontro Nacional. Moscavide: Bens Culturais da Igreja, 2013. p. 133-149.

VAZ, Francisco; CALIXTO, José António. Frei Manuel do Cenáculo construtor de bibliotecas. Casal de Cambra: Caleidoscópio, 2006.

VILHENA BARBOSA, Ignacio de. Bibliothecas. Sua origem e progressos em Portugal até o fim do século XVIII. Estudos historicos e archeologicos. Lisboa: 1874. t. 1. p. 85-117.

VITERBO, Francisco Marques de Sousa. A livraria real especialmente no reinado de D. Manuel. História e Memórias da Academia Real Sciencias de Lisboa, Lisboa, nova série, t. 9, p. I, p. 1-73, 1902.

WILSON-LEE, Edward. The Catalogue of Shipwrecked Books. Young Columbus and the Quest for a Universal Library. London: William Collins, 2019.

350 títulos para a história do livro e da leitura em Portugal. Cultura. Revista de História e Teoria das Ideias, 2 s., v. 9, p. 314-335, 1997.

\title{
A paper tradition: Tracing the history of ecclesiastical libraries in Modern Portugal
}

\begin{abstract}
This work aims to discuss the definition of ecclesiastical library in the Portuguese bibliographic panorama using the concept/function of selection. The starting point is a full-scale research with the aim of locate, identify and study all extant library catalogues and inventories of more than 400 Portuguese religious institutions. The database resulted from this research has more than 900 bibliographic records. The article opens with a brief bibliographical review on the issues that have involved the evolution of the history of libraries in Portugal. In the second part, is presented the extensive network of Portuguese ecclesiastical libraries. The third part shows how the selection function affected the internal functioning of ecclesiastical libraries throughout their secular existence. The fourth part analyzes the dispersion of ecclesiastical libraries as a
\end{abstract}


result of external selective processes (1759-1834). The conclusions highlight the importance of the historical reconstruction of book collections and the intrinsic vitality of the ecclesiastical library.

Keywords: Religious congregations. Catalogs, inventories and bibliographies. Collections. History of Book. Secularization.

Recebido: $16 / 05 / 2019$

Aceito: 25/06/2019

${ }^{1}$ Em 1698, os Franciscanos da Província de Santa Maria de Arrábida definiam a biblioteca com as seguintes palavras: "nesta Província se entenderá por livraria não só a casa commua aonde os livros se guardão, mas qualquer cella ou lugar do Convento em que qualquer livro se achar e estiver posto". Texto citado a partir de GIURGEVICH-LEITÃO 2016, DOC. 157.

${ }^{2}$ O texto do ANSELMO 1923 tinha uma secção que incluía cerca de 40 catálogos de bibliotecas de instituições religiosas localizados entre a Biblioteca Nacional de Portugal e a Biblioteca Pública de Évora.

${ }^{3}$ Para uma bibliografia detalhada reenvia-se a GIURGEVICH-LEITÃO 2016.

${ }^{4}$ Uma obra clássica neste gênero é considerado o Liber de scriptoribus ecclesiasticis, da autoria do monge beneditino Johannes Trithemius e publicada em Basileia em 1494.

${ }^{5}$ A título de exemplo, veja-se o catálogo da biblioteca do Convento de Nossa Senhora da Graça de Lisboa, que refere os livros perdidos no terramoto: GIURGEVICH-LEITÃO 2016, INV. 260.

${ }^{6}$ Sobre os folhetos volantes, ver por exemplo o cuidado da descrição do catálogo da biblioteca do Mosteiro de São Martinho de Tibães, GIURGEVICH-LEITÃO 2016, INV. 74.

7 Os catálogos da biblioteca de Tibães são descritos e inventariados em: GIURGEVICHLEITÃO 2016, INVS. 71-79.

8 Os catálogos da biblioteca da Casa das Necessidades encontram-se referenciados em: GIURGEVICH-LEITÃO 2016, INVS. 815-850.

${ }^{9}$ Sobre esta interligação, ver, por exemplo, as regras que geriam as várias bibliotecas dentro de um colégio jesuíta. Documento transcrito em: GIURGEVICH-LEITÃO 2016, DOC. 322.

${ }^{10}$ Os inventariantes trabalharam no catálogo da biblioteca do Colégio de S. Antão ao longo de pelo menos cinco meses. Ver: GIURGEVICH-LEITÃO 2016, DOC. 309.

${ }^{11}$ Ver a carta de doação dos bens do Colégio de Cotovia ao Colégio dos Nobres. Os autores mais procurados eram Luís Camões, João de Barros e André Resende. Documento consultado in: Arquivo Histórico Ultramarino, CU, Reino, cx. 17, pasta 21 [cópia].

$12 \mathrm{O}$ modelo dividia os livros em classes de saberes (teologia, jurisprudência, filosofia, matemática, medicina, história e belas letras): os livros eram listados por ordem alfabética dentro de seções determinadas por formato e assunto. Os livros, ainda, eram descritos detalhadamente fornecendo os dados necessários para a identificação da edição (nome do autor, título da obra, número de tomos e de edições, local e data de impressão).

13 Ver, em particular, o artigo número 10 das Instrucções para os inventários das casas religiosas. Documento transcrito por GIURGEVICH-LEITÃO 2016, DOC. 346.

${ }^{14}$ Só nos casos em que o catálogo de livraria faltasse se redigiam inventários ex-novo. Ver, por exemplo, GIURGEVICH-LEITÃO 2016, INV. 58.

15 São adjetivos usados frequentemente nos documentos para enquadrar as coleções de livros. Cada comissão era composta de um juiz inventariante, um comissário fiscal, um ou mais escrivães, as cabeças de casal (ou inventariantes), os louvados, os depositários e várias testemunhas. Os inventariantes, ou informadores locais eram os próprios religiosos. 